\title{
SUPERENDIVIDAMENTO EM PERSPECTIVA: UMA ANÁLISE DO FENÔMENO A PARTIR DOS CONTEXTOS SOCIAL E JURÍDICO.
}

\author{
Fernanda Holanda de Vasconcelos Brandão ${ }^{1}$ \\ Luiz Mesquita de Almeida Neto ${ }^{2}$
}

\section{RESUMO:}

O presente artigo estuda o tema do superendividamento. Como método, propõe uma abordagem indutiva, pautada por critério contextual, classificativo. O objetivo é extrair contribuições para a atualidade da questão, enfocando consequências da abordagem utilizada, particularmente associada a uma realocação de debates sobre a matéria, para contemplar uma dimensão econômica, com efeitos sociais mais generalizados que os tradicionais debates jurídicos tratam. Neste ponto, destaca-se a análise do superendividamento relativamente aos direitos sociais, afetando a realização destes, para se defender ao final medidas jurídicas cabíveis sobre a prevenção do fenômeno e a necessidade de conscientização dos consumidores.

Palavras-chave: Superendividamento; Consumidores; Direitos sociais; Questões jurídicas; Contexto social e econômico.

\section{OVER-INDEBTEDNESS IN PERSPECTIVE: AN ANALYSIS ABOUT THE PHENOMENON FROM SOCIAL AND LEGAL CONTEXTS.}

\begin{abstract}
:
The current article studies the over-indebtedness theme. Like method, proposes an inductive approach, ruled by contextual, classificatory standard. The goal is to extract contributions to the actuality about the issue, focusing consequences from the used approach, particularly linked to a reallocation of debates about the matter, to contemplate an economic dimension, with social effects more generalized than the traditional legal debates treat. Hereupon, stands out the over-indebtedness analysis regarding to the social rights, affecting their achievement, to endorse in the end appropriate legal measures about the phenomenon prevention and the need for consumer awareness.
\end{abstract}

Keywords: Over-indebtedness; Consumers; Social rights; Legal issues; Social and economic context.

\section{INTRODUÇÃ̃O}

\footnotetext{
${ }^{1}$ Doutora e Mestre em Ciências Jurídicas pela Universidade Federal da Paraíba. Possui graduação em Direito pelo Centro Universitário de João Pessoa, em Radialismo em Rádio e TV pelo Centro Federal de Educação Tecnológica da Paraíba e em Comunicação Social - Jornalismo pela Universidade Federal da Paraíba. É professora da disciplina Prática Jurídica do UNIPÊ e da UFPB. Professora permanente do Programa de Pósgraduação em Ciências Jurídicas da UFPB. Editora da Revista Direito e Desenvolvimento do UNIPÊ.

${ }^{2}$ Advogado. Bacharel em Direito pela Universidade Estadual da Paraíba. Especialista em Direito pela Damásio Educacional. Mestrando no Programa de Pós-Graduação em Ciências Jurídicas da UFPB, concentração em Direito Econômico.
} 
De uma maneira geral, a análise de casos concretos, trazidos à apreciação pelo Direito, é feita através de um cotejo com determinado contexto. A aplicação do Direito deve sempre estar de acordo com a realidade em que o caso e as normas jurídicas estão inseridos. Especialmente, esta noção de contextualização do Direito tem sido muito relevante para o Direito Civil, que tem redefinido seus institutos e regras, em atenção ao texto constitucional e a uma realidade social e econômica que dita uma transformação muito intensa na aplicação de normas com natureza jurídica eminentemente privada. É assim que se fala, atualmente, em “Constitucionalização” do Direito Civil, por exemplo.

O presente artigo trata justamente do problema relativo à alocação classificativa e relevância temática do "superendividamento", que vem a ser o seu tema central. Busca realizar tal estudo especialmente focalizando a relação desta temática com outras matérias tangenciais e pertinentes, às quais é relacionado em sentido de contextualização. Assim, tratase do sobre endividamento dos consumidores à luz da realidade social do mercado de consumo contemporâneo, sob a ótica da dogmática tradicional do direito obrigacional civilista e, ainda, em cotejo com a construção dos direitos sociais na economia atual, e a pertinência da efetivação destes com a função de crédito.

Os objetivos do trabalho são, basicamente, debater as possibilidades de redefinição da abordagem do tema central "superendividamento" na teoria do Direito, primeiramente discutindo sua relevância para os contextos social e jurídico afetados pelas suas implicações e, em segundo lugar, tratando da proeminência da questão inclusive para a economia, em uma dimensão mais abrangente de Direito Econômico, visualizada pela aptidão endêmica e nociva que o fenômeno pode vir a caracterizar na realidade do crédito e sua consequente relação com a dinâmica de mercado na efetivação de direitos sociais.

A justificativa para os presentes esforços se subdivide em duas acepções. Socialmente, é extraída da constatação do grande número de casos de endividamento dos consumidores, que se percebe dos altos patamares sociais estatísticos da população que se contempla em situação de inadimplemento de obrigações. Ou seja, o tema é relevante porque se apresenta de maneira frequente e constante na sociedade.

A justificativa teórica reside na tentativa de realocar os debates sobre o "superendividamento" em uma perspectiva distinta daquela que tradicionalmente enfrenta a 
questão, para além de construções sobre aspectos endógenos de uma relação jurídica privada, que focam sua análise nos direitos humanos essenciais da pessoa endividada, busca alcançar o estudo do fenômeno em perspectiva com contextos social e jurídico distintos, mais amplos, contextualizando-o e extraindo daí possibilidades do enfrentamento da questão inclusive para a realidade econômica mais ampla e subjacente através, sobretudo, da relação crédito / direitos sociais / superendividamento.

A metodologia utilizada é a indutiva, a partir da coleta de dados através de pesquisa bibliográfica, eminentemente através da análise normativa e doutrina especializada, particularmente pautada por uma construção classificativa e com o escopo de contextualização do tema central acima mencionado.

\section{O PROBLEMA DO SUPERENDIVIDAMENTO}

De maneira introdutória, cumpre tecer considerações preliminares acerca do superendividamento. Com relação a este, nota-se que doutrina e jurisprudência têm se firmado, hodiernamente e cada vez mais, no sentido de garantir ao devedor, em casos onde este se encontra com suas finanças comprometidas além de suas capacidades, com obrigações de natureza eminentemente civil e/ou consumerista, medidas que, postergando ou alterando as cláusulas ou condições de adimplemento, possam estabelecer parâmetros mínimos de subsistência e de condições dignas para o cidadão.

É um tema muito complexo, e que suscita um profundo debate, especialmente no campo ético e moral. De um lado, sob o ângulo do credor, passa-se à argumentação de que o inadimplemento deve ser visto como algo negativo, a ser reprimido em toda circunstância, e que a medida de atenuar, de qualquer maneira, a força obrigatória dos contratos, leva a uma inevitável insegurança jurídica, tendo-se, neste contexto, o reforço argumentativo de que o devedor não seria - pelo menos em tese, e a princípio - compelido à situação, aderindo aos pactos que o vitimam a partir de sua própria iniciativa.

Por outro lado, pela ótica do devedor, comparam-se as obrigações assumidas, na ordem civil / consumerista, a outros valores - presumivelmente mais fundamentais -, quase sempre fundados na dignidade humana, onde esta, afetada, torna necessária a adoção de 
medidas jurídicas excepcionais que, a despeito de relativizarem cláusulas de negócios jurídicos, acabam, no caso concreto, servindo para garantir direitos elementares e básicos, caros ao próprio Estado em si (em geral, direito à moradia, direito à remuneração e sua proteção, impenhorabilidade de patrimônio mínimo, etc.) e, portanto, anteriores ao contrato que fundamenta a relação entre as partes.

No Brasil, o superendividamento tem sido enfrentado, já há alguns anos, no campo do Direito do Consumidor, com destaque para a obra da autora Claudia Lima Marques. Esta eminente professora, partindo da obra de Natalino Irti (Teoria generali Del diritto e problema Del mercato, em uma análise do direito privado atual em suas relações com a realidade econômica) e de Giorgio Oppo ("squilibrio" contratual), avalia a problemática do superendividamento, inclusive conceituando-o, da seguinte forma:

\footnotetext{
Efetivamente, o endividamento é um fato inerente à vida em sociedade, ainda mais comum na atual sociedade de consumo.

Para consumir produtos e de serviços, essenciais ou não, os consumidores estão quase todos - constantemente se endividando. A nossa economia de mercado seria, pois, por natureza, uma economia do endividamento. Consumo e crédito são duas faces de uma mesma moeda, vinculados que estão no sistema econômico e jurídico de países desenvolvidos e de países emergentes, como o Brasil.

O superendividamento pode ser definido como a impossibilidade global do devedor - pessoa física, consumidor, leigo e de boa-fé, de pagar todas as suas dívidas atuais e futuras de consumo (excluídas as dívidas com o Fisco, as oriundas de delitos e as de alimentos). Este estado é um fenômeno social e jurídico, a necessitar algum tipo de saída ou solução pelo direito do consumidor, a exemplo do que aconteceu com a falência e a recuperação judicial e extrajudicial no direito da empresa, (....). ${ }^{3}$
}

Do próprio conceito advindo da exposição citada acima, já se percebe a relação entre a problemática do superendividamento e a ordem econômica, assim como sua implicação como fenômeno tanto jurídico como social.

De maneira quase axiomática, pode-se inferir que o fenômeno do superendividamento se situa, quanto a sua análise jurídica, no plano das obrigações. Assim, verifica-se que o fenômeno é observado nas relações envolvendo obrigações, geralmente

\footnotetext{
${ }^{3}$ MARQUES, Claudia Lima. Contratos no Código de Defesa do Consumidor: o novo regime das relações contratuais. 5. ed. São Paulo: Editora Revista dos Tribunais, 2005. (p. 1236).
} 
pautadas por um diálogo das fontes que, via de regra, envolve o Direito Civil e o Direito do Consumidor ${ }^{4}$.

A relação obrigacional, por sua vez, desenrola-se, atualmente, em uma dinâmica que envolve um aspecto subjetivo (as partes), objetivo (a prestação, imediatamente, e o bem da vida, mediatamente), e, por último, um elemento imaterial, virtual ou espiritual da obrigação 5 .

\subsection{O contexto dogmático - jurídico do fenômeno do superendividamento}

O elemento imaterial, virtual ou espiritual da obrigação ${ }^{6}$, que vem a constituir o terceiro elemento da relação jurídica obrigacional, é o vínculo jurídico, existente entre as partes, para regular os direitos e deveres a que cada parte faz jus no sinalagma. Basicamente, este elemento corresponde ao liame que une as partes. Como já dito acima, o seu conteúdo, na prática do dia a dia dos contratos, tem sido preenchido, via de regra, por um diálogo das fontes entre o Direito Civil e o Direito do Consumidor.

Atualmente, após um primeiro momento de influência de uma teoria conhecida como "monista" ou "unitária" (compreendia o elemento como uma coisa só, única), passou-se ao tratamento deste elemento da obrigação, com base em uma construção contemporaneamente mais aceita, denominada de teoria dualista ou binária, que divide a relação jurídica em si, e onde tal vínculo possuiria natureza dúplice. Neste ponto, diz-se que a relação dá ensejo, de imediato, a um débito (um dever, uma dívida), estipulada contratualmente, ao qual o devedor se obriga - o termo em alemão, utilizado para designar este "débito" é consagrado como Schuld. Mas, em outro ponto, esta relação obrigacional também gera uma responsabilidade -

\footnotetext{
${ }^{4}$ TARTUCE, Flávio. Manual de direito civil: volume único. 4.ed. Rio de Janeiro: Forense / São Paulo: Método. 2014. (pp. 61-62).

${ }^{5}$ Sobre os elementos essenciais da relação obrigacional: GAGLIANO, Pablo Stolze; PAMPLONA FILHO, Rodolfo. Novo curso de direito civil, volume 2: obrigações. 16. ed. São Paulo: Saraiva, 2015. (pp. 55-59).

${ }^{6}$ Acerca deste tema: TARTUCE, Flávio. Direito civil, v. 2: direito das obrigações e responsabilidade civil. 11. ed. Rio de Janeiro: Forense; São Paulo: MÉTODO, 2016. (pp. 10-16).
} 
para o caso de descumprimento do pacto, pela impossibilidade da prestação - onde a responsabilidade, no termo em alemão, é designada pelo vocábulo Haftung $^{7}$.

É plenamente possível a existência de um elemento sem a existência do outro, por onde os dois não são coincidentes (por exemplo, em algumas obrigações negativas não haverá a previsão do Schuld, mas apenas do Haftung, para o caso de descumprimento), mas o mais comum é que se encontrem os dois presentes.

O superendividamento, de uma perspectiva teórica e dogmática, é uma degeneração da relação obrigacional, pela perda, por impossibilidade de realização pelo devedor, tanto do débito (Schuld) quanto da responsabilidade (Haftung), uma vez que o fenômeno não trata como visto no conceito acima - de inadimplemento de uma obrigação, mas da incapacidade global de o consumidor, com todo o seu patrimônio, fazer frente às obrigações que assumiu.

Assim, o patrimônio global do devedor (muitas vezes inclusive preservado, em um patamar mínimo, de impenhorabilidades), que deveria funcionar como uma espécie de garantia para cumprimento da obrigação, através da possibilidade de responsabilização, pela classificação enquanto Haftung, nos termos acima, por exemplo, de acordo com o art. 391, do Código Civil de 2002, encontra-se totalmente comprometido, até os limites que a legislação autoriza (por exemplo, nos termos das impenhorabilidades previstas no art. 833, do Novo Código de Processo Civil, de 2015).

É um caso em que a obrigação, vista atualmente como um processo, pautada por deveres de boa-fé objetiva e da função social dos contratos, precisa ser revista para garantir a sua própria viabilidade, pois, caso contrário, ou se estará diante de uma obrigação que será perdida mesmo (uma vez que se torna inviável em todas as esferas possíveis de responsabilização para o devedor) ou continuará, obrigando o devedor em uma situação indigna (aí sim, afetando direitos fundamentais elementares, inerentes à dignidade humana), além das possibilidades que a legislação prevê para seu caso.

Desta maneira, dependendo da circunstância do caso concreto, o superendividamento pode representar uma séria ofensa à dignidade humana do devedor (que porventura continue adimplindo obrigações além de suas capacidades, prejudicando até mesmo sua subsistência)

\footnotetext{
${ }^{7}$ Mais uma vez, sobre a questão, veja-se: GAGLIANO, Pablo Stolze; PAMPLONA FILHO, Rodolfo. Novo curso de direito civil, volume 2: obrigações. 16. ed. São Paulo: Saraiva, 2015. (pp. 55-59).
} 
ou, em outro cenário, pode significar um grande prejuízo para o credor (casos em que o devedor se torna inadimplente e, pela inviabilidade de qualquer patrimônio penhorável, a obrigação perde, por impossibilidade, tanto o Schuld quanto o Haftung).

É justamente pelo fato de o credor possuir eventual interesse na solução de muitos casos de superendividamento (em que, caso não seja apresentada uma alternativa viável, a obrigação será perdida sem nenhuma hipótese de responsabilidade do consumidor) que há casos de composição autônoma amigável, através de programas de solução judicial ou extrajudicial, de casos de superendividamento bem sucedidos noticiados Brasil afora ${ }^{8}$.

\subsection{O contexto sociocultural do fenômeno do superendividamento}

Contudo, é de se dizer que o mero inadimplemento contratual, de um devedor consumidor -, pessoa física, em um contrato onde não fosse possível realizar a obrigação por nenhuma forma - ante a total falta de patrimônio do devedor - não é nenhuma novidade no universo jurídico. A alocação conceitual, dogmática e jurídica, acima exposta, corresponde à descrição de um fenômeno muito antigo, qual seja: o inadimplemento absoluto.

O que acrescenta ao tema, e o torna relevante, no caso do superendividamento, são as circunstâncias socioculturais, que fazem com que o estado de insolvência global, do consumidor - pessoa física - de boa-fé, seja muito comum e freqüente. O que tornou relevante a matéria foi exatamente a observação de que, na sociedade contemporânea, muitos consumidores passaram a apresentar padrões de endividamento vertiginoso, com muita recorrência no número de indivíduos "superendividados".

A doutrina tem apresentado vários fatores, socioculturais, que servem tanto para explicar a ocorrência quanto para fundamentar o enfrentamento da questão, dentre os quais se podem destacar, particularmente, os seguintes: (a) ressignificação do papel do contrato nas relações sociais; (b) consumismo; (c) A "financeirização" do capital, e; (d) valorização da dignidade humana.

\footnotetext{
${ }^{8}$ Neste sentido, veja-se: BAUERMANN, Sandra. Implantação e experiência do projeto de tratamento ao superendividamento do consumidor no Poder Judiciário do Paraná. Revista de direito do consumidor, São Paulo - Editora Revista dos Tribunais -, a. 23, vol. 95, pp. 231-251, set./out., 2014. (pp. 247-249).
} 
Com relação ao primeiro dos fatores destacados, pode-se dizer que o contrato, originariamente, em tempos idos, de inspiração romana, inseria-se em um contexto da vida cotidiana muito limitado: tratava de relações estritamente privadas (da vida particular, vez que o Estado possuía grande ingerência em assuntos da comunidade) entre iguais (apenas cidadãos romanos, no início) e de maneira "artesanal", por assim dizer - termo se refere ao fato de que as partes efetivamente realizavam negociações e tratativas, expressando suas vontades, que desembocariam, enfim, no título negocial.

Ocorre que, ao longo de muitos séculos, esta realidade original foi sendo alterada, modificada por fatores sociais que influenciam em uma lógica de mercado que se utiliza massivamente do instrumento contratual para as suas trocas ${ }^{9}$.

Entretanto, pode-se destacar, neste cenário, duas principais alterações, indicadas pela doutrina $^{10}$, na dinâmica da relação contratual, quais sejam, a "massificação" e a "desmaterialização" dos contratos. A primeira alteração (ou crise da dogmática clássica dos contratos) refere-se ao fato de que, com os processos econômicos de globalização e expansão do mercado, os contratos passaram a massificar-se e a reger, indistintamente, a relação entre empresas e consumidores, agravando-se o fenômeno em virtude da circunstância de que, pela natureza do processo de produção capitalista, os títulos negociais precisam ser pré-redigidos, com determinadas cláusulas imutáveis, às quais o consumidor apenas adere (extraindo da prática da relação o elemento volitivo originariamente concebido como essencial à feitura do ato em si, restando presente atualmente apenas a adesão a um ato pré-fabricado).

A segunda alteração, ou crise, consiste no fato de que, sobretudo a partir do desenvolvimento efetivo do comércio eletrônico ${ }^{11}$, a própria identidade, e o vínculo, existentes entre as partes que estão negociando, foi esvanecendo, ao ponto em que, nos dias atuais, foram muito relativizados tanto o elemento anímico - a manifestação da vontade do consumidor, que apenas adere ao contrato - quanto a relação jurídica em si - pois muitas

\footnotetext{
${ }^{9}$ Sobre o tema, leia-se: TARTUCE, Flávio. Manual de direito civil: volume único. 4. ed. Rio de Janeiro: Forense; São Paulo: MÉTODO, 2014. (pp. 579-581).

${ }^{10}$ MARQUES, Claudia Lima. Contratos no Código de Defesa do Consumidor: o novo regime das relações contratuais. 5. ed. São Paulo: Editora Revista dos Tribunais, 2005. (pp. 64-71).

${ }^{11}$ LORENZETTI, Ricardo Luis. Comércio eletrônico. Trad. Fabiano Menke. Notas Claudia Lima Marques. São Paulo: Editora Revista dos Tribunais, 2004.
} 
vezes as partes sequer chegam a se conhecer, nem muito menos desenvolver qualquer tratativa.

Por tais questões, o papel do contrato, na realidade social, passou por um processo de ressignificação, tornando necessária a construção de um novo parâmetro para aferição de abusividades, bem como novas possibilidades para a revisão dos negócios jurídicos ${ }^{12}$.

O segundo aspecto apontado - o consumismo - trata de uma cultura, popular e massificada, de estímulo à prática do consumo irresponsável e irrefletido. Neste ponto, tem-se que os fornecedores, em um cenário de expansão constante do mercado, e necessidade de manutenção de procura por seus produtos e serviços, tendem a utilizar-se de meios como a cultura e, principalmente, a propaganda, para criar na sociedade em geral um apelo pela sua procura. Muitas décadas de desenvolvimento desta prática levaram a uma cultura popular permeada por estes apelos, que resulta em um cenário cotidiano de estímulo à aquisição de produtos e serviços que guardam pouca relação com as necessidades práticas e cotidianas dos consumidores. Em estudo empírico interessantíssimo, que muito reflete esta realidade, a pesquisadora Márcia Amaral Corrêa de Moraes, inclusive já diante da potencialidade de proliferação deste fenômeno no meio digital, observa que:

O estudo aqui apresentado revela que estudantes jovens e adultos, no contexto investigado, incorporaram a navegação virtual em seu cotidiano e, portanto, operam intelectualmente de modo "malabarista". Neste sentido, são alvo relativamente fácil das ações publicitárias, na medida em que não têm consciência de sua fragilidade nessa relação: cidadão / consumidor X propaganda / aumento e acúmulo de capital. Apostando na difusão do sentimento de protagonismo, o universo virtual age de forma perversa do ponto de vista do consumo porque se utiliza, inclusive, do tráfico de informações pessoais para, de forma subliminar e inconsciente, conduzir o sujeito à ação desejada pela mídia. ${ }^{13}$

Portanto, o consumismo, enquanto predisposição de ânimo inclinada ao consumo irrefletido, relaciona-se diretamente com a necessidade, ou com a consequência, de contratos aos quais o indivíduo apenas adere, através de cláusulas pré-formuladas.

\footnotetext{
${ }^{12}$ Sobre as transformações na dinâmica dos contratos na sociedade atual, veja-se: (a) MACEDO JUNIOR, Ronaldo Porto. Contratos relacionais e defesa do consumidor. São Paulo: Editora Revista dos Tribunais, 2007. Ou, ainda: (b) SALLES, Raquel Bellini de Oliveira. O desequilíbrio da relação obrigacional e a revisão dos contratos no Código de Defesa do Consumidor: para um cotejo com o Código Civil. In: Obrigações: estudos na perspectiva civil - constitucional. Rio de Janeiro: Renovar, 2005. (pp. 303-332).

${ }^{13}$ MORAES, Márcia Amaral Corrêa de. O impacto da mídia publicitária e relacional na formação de consumidores jovens e adultos. In: Revista luso-brasileira de direito do consumo. Curitiba - Editora Bonijuris, J.M. Editora, vol. II, n. 3 - n. 7 - pp. 95-111, jul./set., 2012. (p. 110).
} 
O terceiro aspecto que se destaca deste contexto sociocultural vem a ser a "financeirização" do capital ${ }^{14}$. Este termo faz menção ao fato de que, sobretudo a partir da década de 1970, o capitalismo mudou muito em sua feição, passando a relegar a um papel secundário o setor de produção, permitindo a prevalência de produtos e serviços financeiros, ou seja, de negócios creditícios, cada vez mais complexos e que, a partir da prática do consumo pelo indivíduo, exploram as finanças pessoais, de uma maneira tanto mais complexa quanto potencialmente mais lucrativa, fazendo com que este setor financeiro protagonize os ditames do mercado global.

A complexidade dos produtos financeiros oferecidos na atualidade tem sido, inclusive, associada a diversas crises que se tem visto nas economias dos países, e na economia global ${ }^{15}$.

Uma das manifestações desta realidade econômica, ou um dos sintomas da financeirização da economia - se se preferir desta forma - é, exatamente, o superendividamento dos consumidores que chegam a uma realidade (associada aos fatores anteriormente expostos, e especialmente atrelada a uma cultura consumista) em que suas rendas pessoais estão comprometidas com produtos financeiros (operações de crédito, geralmente de longo prazo) de uma forma tal que não é possível a subsistência do indivíduo naquele patamar.

Como uma das maiores manifestações do fenômeno, a própria OECD admitiu, em seu relatório intitulado "The financial crisis: reform and exit strategies" ${ }^{16}$, que um dos princípios de reforma para superar a crise (financeira, conforme se nota do próprio título do documento) seria, justamente, tentar enfrentar a alta complexidade dos produtos financeiros, e tomar normas e medidas que protejam os consumidores neste contexto.

\footnotetext{
${ }^{14}$ Sobre o capitalismo de base financeira, veja-se: LAPAVITSAS, Costas. El capitalismo financiarizado: Expansión y crisis. Trad.: Diego Guerrero. Madrid: Maia Ediciones, 2009.

${ }^{15}$ Sobre as crises do capital, contextualizando com a nova realidade exposta a partir da crise de 2008, veja-se: FONSECA, João Bosco Leopoldino da. Direito econômico. Rio de Janeiro: Forense, 2010. (pp. 299-305).

${ }^{16}$ Organisation for Economic Co-operation and Development (OECD). The financial crisis: reform and exit strategies. Disponível em: http://www.oecd.org/daf/fin/financial-education/43091457.pdf. Acesso em: 07 set. 2016.
} 
O último fator apontado seria justamente a valorização da dignidade humana, realçada como quarto fator sociocultural para o enfrentamento do problema do superendividamento. Neste ponto, verifica-se que a evolução jurídica como um todo tem concebido que o Direito deve se pautar por valores éticos tendentes a respeitar a dignidade do indivíduo quanto a sua convivência em sociedade. Esta noção se aplica a todos os ramos do Direito, que se humanizam e passam a respeitar, além das normas jurídicas postas e atinentes ao seu ramo, uma dimensão sobreposta de valores éticos, geralmente extraídos da Constituição através de princípios, que respeitam a condição do sujeito de direitos enquanto ser humano, com a finalidade ideológica de garantir o respeito à sua dignidade.

No tocante ao consumidor endividado, importante construção é a noção, ampla em relação a este ponto, e aplicável aos direitos fundamentais como um todo, de mínimo existencial $^{17}$, que toca a prestações indispensáveis, sem as quais um indivíduo não conseguiria realizar um padrão mínimo de subsistência digna. Por outro lado, especialmente no ponto relacionado ao devedor consumidor inadimplente, aperfeiçoou-se a construção do patrimônio mínimo ${ }^{18}$, consistente em uma tutela jurídica de garantia (inviolabilidade) de parcela do patrimônio do devedor sem a qual este não conseguiria subsistir, geralmente sistematizadas, em nossa tradição jurídica, nas regras de impenhorabilidade dispostas nos diplomas processuais civis brasileiros - atualmente, constam do art. 833, do Código de Processo Civil.

\subsection{O superendividamento e os direitos sociais}

Esta relação, entre patrimônio mínimo e o instituto do superendividamento, que é muito recorrente na prática (no mais das vezes, as execuções ajuizadas contra devedor insolvente, assaz endividado, guarda como obstáculo o patrimônio impenhorável deste), traça uma interseção temática que, na verdade, é a ponta de um iceberg sobre o qual a questão do crédito se encontra assentado.

Ocorre que o conteúdo do patrimônio mínimo, e consequentemente do mínimo existencial do qual decorre, não é outro senão uma gama de direitos sociais intangíveis em

\footnotetext{
${ }^{17}$ SARLET, Ingo Wolfgang. A Eficácia dos direitos fundamentais. Porto Alegre: Livraria do Advogado, 2005.

${ }^{18}$ FACHIN, Luiz Edson. Estatuto jurídico do patrimônio mínimo. 2. ed. Rio de Janeiro: Renovar, 2006.
} 
virtude de sua essencialidade a uma existência digna. São condições materiais elementares a um padrão digno de existência. Aqui é importante destacar que, não obstante a relevância das classificações para fins didáticos - particularmente no estudo do Direito Constitucional -, o conteúdo social (como direito a uma prestação material de ordem elementar) dos direitos fundamentais ou humanos nunca pôde ser dissociado, na prática e de fato, dos direitos assim tidos por individuais, que prescreviam uma abstenção por parte do Estado. São faces de uma mesma moeda, intrinsecamente conectados. Assim, note-se que:

(...) a modalidade conceitual que nega o caráter jurídico dos direitos sociais, para limitá-los a meras "políticas", combina em sua definição uma função política de integração social com sua caracterização como direitos particulares - seja quanto ao objeto (prestações materiais), seja no tocante à categoria de sujeitos beneficiários (os indigentes). (...).

\section{(...)}

(...). À medida em que esta conexão entre direitos sociais e mudança social se debilita, especialmente depois de 1945, com a generalização (relativa) de um modelo de Estado social, por um lado, e a aceitação definitiva (também relativa) dos direitos sociais no Direito Constitucional, por outro, sua significação teórica e jurídica se transformará. ${ }^{19}$

Carlos Miguel Herrera destaca que desde a constituinte reunida em virtude da revolução francesa, os direitos sociais foram concebidos conjuntamente aos direitos individuais, como se percebe a seguir:

(...), o Comitê declara que ali onde se encontrem homens sem meios de subsistência, existe uma violação dos direitos do homem. Num discurso de 1792, Bernard precisa que o direito à subsistência apresenta dois aspectos: o trabalho, se o homem é apto, ou os auxílios gratuitos, se não tem a possibilidade de fazê-lo. ${ }^{20}$

Aqui, é importante lembrar, em complemento a esta noção, que a obra constitucional contemporânea elabora distinção, em uma classificação pertinente a este estudo, entre os direitos sociais típicos de trabalhadores (que estariam insculpidos entre os arts. $7^{\circ}$ a 11 , da Constituição da República) e aqueles típicos do consumo (saúde, educação, segurança social, entre outros) $)^{21}$.

\footnotetext{
${ }^{19}$ HERRERA, Carlos Miguel. Estado, constituição e direitos sociais. In: Revista da Faculdade de Direito da Universidade de São Paulo. São Paulo - USP, vol. 102, pp. 371-397, jan./dez., 2007. (pp. 373-374).

${ }^{20}$ Id. Ibid., p. 375.

${ }^{21}$ SILVA, José Afonso da. Curso de direito constitucional positivo. 32. ed. São Paulo: Malheiros Editores, 2009.
} 
A dinâmica na persecução à realização destas prestações materiais (conceitualmente inseridas no tópico de direitos sociais), contudo, se originariamente fora uma demanda estabelecida em face exclusivamente do Estado, com o avanço do mercado e as possibilidades que as instituições financeiras galgaram ofertar, paulatinamente, foi se transferindo, de maneira cada vez mais acessível a camadas populares menos favorecidas, para a função de crédito. Ou seja, em uma relação tipicamente particular (entre um indivíduo e uma instituição financeira, ou algum outro conglomerado empresarial, prioritariamente), tornou-se possível a realização de prestações materiais que se conectam com necessidades inerentes à própria condição humana. Assim é que, por exemplo, o direito social à moradia passou a ser corriqueiramente objeto da concessão de crédito. Dito de melhor forma, é possível refletir um pouco sobre este tópico no seguinte referencial:

O crédito, sem dúvida, cumpre importante papel econômico e social, a saber: (a) possibilita às empresas aumentarem seu nível de atividade; (b) estimula o consumo influenciado na demanda; (c) ajuda as pessoas a obterem moradia, bens e até alimentos; e (d) facilita a execução de projetos para os quais as empresas não disponham de recursos próprios suficientes. A tudo isso, entretanto, deve-se acrescentar que o crédito pode tornar empresas ou pessoas físicas altamente endividadas, assim como pode ser forte componente de um processo inflacionário. ${ }^{22}$

O consumo, portanto, é, conceitualmente, um meio de satisfação de necessidades materiais. É possível potencializar, de maneira superficial, as condições de consumo do indivíduo através da função do crédito - o que é do mais alto interesse social, sem dúvida -, porém, o ponto, em complemento ao que já foi exposto no subitem 2.2, acima (quando se tratou especificamente da "financeirização do capital"), é que a função financeira é envolta nas condições de risco / retorno, o que demanda que a instituição financeira (ou outro agente econômico que lhe faças as vezes) seja criterioso na oferta e, principalmente, na concessão de recursos através da modalidade de crédito.

Obviamente, o agente econômico precisa, já de saída, ser criterioso para evitar sofrer um prejuízo e, oferecendo crédito sem critério, contratar o serviço com um consumidor que, pelo seu próprio perfil, não teria condições de arcar com as condições ali estabelecidas. Também o consumidor precisa realizar a operação de maneira criteriosa, ou então restará em condição de inadimplência com todas as sanções e restrições daí advindas.

\footnotetext{
${ }^{22}$ SILVA, José Pereira da. Gestão e análise de risco de crédito. 6. ed. São Paulo: Atlas, 2008. (p. 50).
} 
A análise sob a ótica do consumidor, e do ponto de vista do agente econômico, e como as implicações desta relação mútua degenera em frequentes casos de superendividamento, é interessante, e pertinente. Porém, o que significa para o Estado que seus consumidores estejam superendividados? A resposta é óbvia: retração de consumo. A verdade é que o consumidor em débito ingressa em um serviço de proteção ao crédito que, de mais a mais, impede-lhe de contratar novos produtos financeiros até que tenha sanado o problema anterior. Porém veja que, no caso do consumidor "superendividado", o problema anterior na função de crédito é insanável por suas próprias forças (este fator compõe o próprio conceito, acima exposto). O fenômeno social chamado "superendividamento" significa, então, para o Estado, a retração no consumo - ou, ao menos, a impossibilidade de contratação de novos produtos financeiros.

A função consumo, por sua vez, desde a obra do notável economista John Maynard Keynes $^{23}$, foi alçada à condição de maior vetor de rendimento, onde, em releitura mais contextualizada deste tópico, pode-se dizer que:

Nos Estados Unidos, as despesas dos consumidores representam cerca de 65 por cento do PNB e, portanto, qualquer análise dos factores que determinam o nível do PNB tem de, numa dada altura, considerar as despesas de consumo. Keynes, em 1936, tornou, analiticamente, a função consumo no elemento principal da determinação do rendimento, através da abordagem do rendimento na óptica da despesa. Vimos, (...), que a função consumo é a estrutura principal da análise do multiplicador. ${ }^{24}$

O que significa que o crédito e o consumo possuem uma relação ambígua, onde é possível, por um lado, injetar recursos de maneira interessante, a partir do crédito, para expandir a capacidade de consumo do cidadão, mas, por outro lado, também é possível endividar o consumidor e, assim, retrair o consumo e, sob a ótica do Estado, inviabilizar uma série de estratégias de desenvolvimento. O ponto decisivo para que o consumo e o crédito possuam convívio salutar reside na análise criteriosa para a concessão deste último, um fator que, sobretudo após meados da década de 1970, tem sido profundamente afetado, como se pode observar do seguinte:

\footnotetext{
${ }^{23}$ KEYNES, John Maynard. The general theory of employment, interest and money. Cambridge: The Royal Economic Society (Maximilian), 1973.

24 BRANSON, William H. Macroeconomia: teoria e política. 2.ed. Lisboa: Fundação Calouste Gulbekian, 2001. (p. 335).
} 
Inovações representam, assim, novidades. Como toda novidade, inovações são, em si mesmas, fontes de incerteza, para quem as introduz (porque não se sabe se os clientes vão aceitá-las ou não) tanto quanto para quem as utiliza (porque não há como ter certeza de que as novas cláusulas respondem mesmo melhor às demandas de cada um ou se não há, implícita em alguma cláusula, alguma disposição adversa que implique custos posteriores etc.). Muito mais do que ocorre com novos produtos industriais, por exemplo, que podem ser examinados concretamente e ter sua performance determinada no momento em que se tornam disponíveis, inovações financeiras são, como vimos, contratos, sobre cujos efeitos, no presente, só se pode especular. (...). Por esta razão, tradicionalmente a atividade financeira tendia a ser desempenhada de forma muito conservadora, com as instituições financeiras, como bancos, por exemplo, preferindo enfatizar sua solidez mais do que sua disposição a correr riscos para buscar maiores retornos. (...).

Essa situação se alterou profundamente a partir da década dos 1970. Inaugurou-se naquela década um período de volatilidade dos mercados financeiros, por causa de diversos fatores a serem identificados mais adiante, que criou um prêmio para aquelas instituições financeiras mais capazes de desenvolver novas respostas para desafios que se diferenciavam a cada momento, desdobrando-se em novos desafios, e colocando novas demandas para as instituições, continuamente. ${ }^{25}$

Esta realidade pode ser facilmente verificada em diversas pesquisas sociais, que deixam claro o aumento do padrão de endividamento da população. Em pesquisa realizada recentemente, mencionada aqui apenas a título de exemplo, a Confederação Nacional do Comércio aferiu que $60,8 \%$ das famílias brasileiras se encontravam em situação de endividamento, número que ainda era ligeiramente maior (em torno de $62,4 \%$ ) no tocante às famílias com renda inferior a 10 salários mínimos ${ }^{26}$.

O que se está descrevendo nesta seção do trabalho é que o casuísmo e a análise individualizada da situação de endividamento, a partir do prisma de cada consumidor endividado, muito embora seja um tratamento extremamente relevante, não cuida do efeito sistêmico e pernicioso que o superendividamento de consumidores (especialmente nos patamares em que se encontra atualmente, em número elevado de casos na população) possui sobre a realidade do tema dos direitos sociais, uma vez que o crédito se relaciona diretamente com esta temática, e assim afeta a concretização destes direitos ou, ainda, vulnera prestações materiais (direitos sociais) anteriormente conquistadas, e, além do mais, atua sobre a retração de consumo e seu efeito consequentemente devastador sobre a economia de um país.

\footnotetext{
${ }^{25}$ CARVALHO, Fernando J. Cardim de et al. Economia monetária financeira: teoria e política. 2. ed. Rio de Janeiro: Elsevier, 2007. (pp. 286-287).

${ }^{26}$ CONFEDERAÇÃO NACIONAL DO COMÉRCIO. Pesquisa Nacional de Endividamento e Inadimplência do Consumidor (PEIC). Disponível em: http://www.cnc.org.br/sites/default/files/arquivos/peic_fevereiro_2016.pdf. Acesso em: 11 mar. 2016.
} 


\subsection{O superendividamento no contexto jurídico positivo brasileiro}

Resultado dos fatores socioculturais acima descritos, e levando em consideração a questão social retratada, o ordenamento jurídico brasileiro tem evoluído, nem sempre na velocidade que se espera, para regulamentar o caso do superendividamento no Brasil. Neste contexto, uma realidade interessante que se tem observado é a situação dos servidores públicos e pensionistas.

Como estas categorias, em geral, particularmente a partir da Constituição da República de 1988, passaram a gozar de estabilidade financeira, e uma vez que sua renda, neste cenário, tornou-se mais valorizada e fixa, este conjunto de potenciais consumidores tornou-se importante fatia do mercado de crédito. Evidenciou-se, inclusive, neste particular, o crescimento do chamado crédito consignado, espécie de negócio jurídico em que o consumidor consegue obter o crédito com juros mais baixos, desde que permitindo a averbação do contrato em sua folha de pagamento, para que seja descontado de maneira automática, sem que o servidor, ou pensionista, possa se furtar, por sua própria escolha, ao adimplemento.

De forma geral, a relação é a de que esta maneira compulsória de adimplemento (automática, diretamente na remuneração do servidor) reduz o risco e, consequentemente, a remuneração do capital, reduzindo por consequência os juros no contrato celebrado. Entretanto, por outro lado, o risco para o consumidor é o de que, tendo suas finanças reduzidas, possa se endividar e, pelo caráter consignado, padecer com necessidades muito básicas - para as quais a sua remuneração serviria - não atendidas, chegando até mesmo a condições indignas.

Neste tópico, as principais normas de combate ao superendividamento no Brasil, em seu estágio inicial, têm sido exatamente estas: normas editadas pela Administração Pública, para regulamentar um patamar máximo de comprometimento da remuneração do servidor, ou do pensionista, com empréstimos consignados, de maneira a limitar a possibilidade de contratação a um padrão máximo, justamente para evitar casos de superendividamento. 
Assim, há um especial destaque para a Lei 10.820/2003, que dispunha, originariamente, em seu artigo $2^{\circ}$, parágrafo $2^{\circ}$, inciso I, que o limite para operações de crédito relativas a empréstimos consignados deve observar o parâmetro máximo de $30 \%$ do valor da remuneração disponível do trabalhador. Esta lei consiste em um importante avanço, porque faz menção aos pensionistas do INSS e aos trabalhadores celetistas, e promove um limite máximo de endividamento, possuindo a intenção de combate ao fenômeno do superendividamento $^{27}$.

Recentemente, contudo, este diploma normativo, da Lei 10.820/2003, passou por diversas alterações legislativas, entre elas aquela constante da Lei 13.172, de 2015, que revisitou a matéria, e alterou os parâmetros, inclusive permitindo uma maior gama de negócios incorporáveis à remuneração do indivíduo (como o arrendamento mercantil, provavelmente de veículos, e despesas com cartão de crédito consignado, à remuneração), e aumentando o limite total, de 30\% para 40\%, no montante global destes negócios jurídicos, incidentes sobre a pensão ou a remuneração do indivíduo.

De qualquer forma, apesar de se perceber um recente aumento nos patamares, e nas possibilidades de incorporação à remuneração dos pensionistas e celetistas, nota-se que o sentido da norma continua sendo o de estabelecer um limite máximo de consignações, justamente para evitar a presença do fenômeno do superendividamento, que comprometa as finanças do cidadão em um montante que lhe afete até mesmo sua subsistência.

Estas disposições, entre outras no mesmo sentido (por exemplo, o art. $8^{\circ}$ do Decreto 6.386/08, que regulamentava o parágrafo único, do art. 45, da Lei 8.112/90, e que foi substituído pelo $\S 2^{\circ}$, do art. 45, da Lei 8.112/90, com redação dada também pela Lei 13.172/2015, para dar tratamento análogo ao da Lei 10.820/2003), têm se firmado no caminho de estabelecer um patamar máximo da remuneração do indivíduo, ao qual o limite das obrigações assumidas, particularmente no contexto dos empréstimos consignados, não pode ultrapassar.

\footnotetext{
${ }^{27}$ BRASIL. Lei Federal $\mathrm{n}^{\circ} 10.820$, de 17 de Dezembro de 2003. Dispõe sobre a autorização para desconto de prestações em folha de pagamento, e dá outras providências. Brasília, DF, 18 Dez. 2003 (DOU). Disponível em: http://www.planalto.gov.br/ccivil_03/leis/2003/L10.820.htm. Acesso em 08 Set. 2016.
} 
A influência destas legislações na cultura jurídica brasileira tem estado prestes a atingir, inclusive, o próprio Código de Defesa do Consumidor, pois o projeto de Lei $\mathrm{n}^{\mathrm{o}} 283$, do Senado Federal, originalmente alterava o art. 54, para adicionar ao seu texto o art. 54- $\mathrm{D}^{28}$, e, assim, passar a prescrever um patamar máximo de 30\% da renda mensal líquida do consumidor como limite máximo de comprometimento com operações de crédito em geral, para expressamente preservar o mínimo existencial. A inspiração nas legislações que tratam de empréstimos consignados é clara, e inclusive os patamares utilizados são semelhantes, entretanto, até o momento, o supramencionado projeto de lei ainda não cumpriu toda a sua tramitação e, assim, não se encontra em vigência.

\section{CONCLUSÕES}

Portanto, a partir do método empregado, é possível fazer inferências muito relevantes acerca da realidade do tema do superendividamento nos dias atuais.

Primeiramente, e como se viu acima, a classificação do tema em um contexto dogmático jurídico permite divisar claramente sua alocação, em termos conceituais, no elemento imaterial da obrigação, afetando tanto o débito quanto a responsabilidade, e apresentando real perigo até de inadimplemento absoluto, e perdimento mesmo, da obrigação.

Esta classificação traz latente a observação de que o enfrentamento do fenômeno do superendividamento não interessa apenas aos consumidores que padecem sem pagar suas contas, como também aos credores, que por vezes ficam diante do cenário de uma economia preenchida por consumidores superendividados que podem simplesmente não honrar seus compromissos por impossibilidade prática e material, o que justifica o sucesso de diversos programas extrajudiciais de composição de débitos (pois os dois pólos, muitas vezes, possuem interesse na solução desta insolvência).

Com relação à análise do contexto sociocultural, percebe-se claramente que o superendividamento não é um fenômeno independente, mas sim a consequência da

\footnotetext{
${ }^{28}$ BRASIL. Senado Federal. Projeto de lei $n^{\circ} 283$. Altera a Lei $n^{\circ} 8.078$, de 11 de Setembro de 1990 (Código de Defesa do Consumidor), para aperfeiçoar a disciplina do crédito ao consumidor e dispor sobre a prevenção do superendividamento. Disponível em: http://www.senado.leg.br/atividade/rotinas/materia/getPDF.asp?t=112479\&tp=1. Acesso em: 08 Set. 2016.
} 
conjugação de diversos fatores que encerram, inclusive, um modo de vida muito popular e constante na contemporaneidade. Essa constatação serve de parâmetro para se notar a relevância do tema, ante a proliferação do fenômeno no meio social, mas também demonstra outro fator: o superendividamento do consumidor é um sintoma de outros problemas estruturais mais amplos, como o consumismo e a financeirização do capital.

A realidade jurídico positiva permite conceber que já há algum tratamento jurídico para o superendividamento. Este tratamento, em geral, consiste na proteção de servidores públicos, pensionistas e trabalhadores em geral, contra negócios jurídicos que são averbados diretamente na remuneração desta modalidade de consumidores. A estratégia da legislação é de estabelecer um parâmetro fixo e objetivo (geralmente em torno de $30 \%$ da remuneração) que não pode ser extrapolado por essa modalidade de negócio jurídico.

Apesar de muito interessante e salutar, esta legislação ainda é muito incipiente. Ocorre que a disciplina não alcança a maioria dos tipos de negócios jurídicos, e restringem seu âmbito de influência apenas aos negócios "consignados" diretamente à remuneração do consumidor, não afetando, por enquanto, contratos como empréstimos pessoais, cartões de crédito, entre outros que, sabidamente, possuem as maiores taxas de juros do mercado e são mais freqüentes no dia a dia da população.

Ocorre que, como já demonstrado nos termos do trabalho, a concessão, irresponsável e sem critérios, de crédito é uma realidade vigente no contexto da atividade financeira dos dias atuais, e seus efeitos nocivos, e sistêmicos, não se restringem a uma relação contratual entre um consumidor e uma instituição financeira, mas agem sobre a função de consumo (retraindo-a fortemente) e, assim, prejudicam o vetor de rendimento, afetando no longo prazo qualquer estratégia de crescimento ou desenvolvimento econômico de países que possuam parcela demográfica significativa de consumidores endividados.

Por tais razões, e com a devida vênia às opiniões em sentido contrário, a aprovação do projeto de lei $\mathrm{n}^{\circ} 283$, que traça linhas gerais de regulamentação nesta matéria, não é um item de interesse apenas do consumidor endividado. É um instrumento de regulamentação de uma falha de mercado relevante, que expõe as economias nacionais a uma situação de instabilidade e prejudica vetores elementares ao desenvolvimento do país. A proposta da lei - 
que tem sido discutida já há alguns anos - não é apenas interessante ao consumidor, como é também fundamental para a ordem econômica brasileira.

De outro lado, uma iniciativa interessante a destacar, que permite trazer alguma esperança em dias melhores ao menos no contexto da educação financeira, que possui efetiva aptidão para enfrentar a questão do consumismo, é a "Escola Nacional de Defesa do Consumidor" que, a partir de relevante iniciativa governamental, tem oferecido cursos de capacitação em matéria de educação financeira básica, especialmente para agentes que atuem na área de defesa do consumidor, aproveitando-se inclusive das ferramentas e possibilidades tecnológicas do ensino à distância, o que aumenta o alcance do projeto.

Espera-se que mais iniciativas análogas sejam estimuladas, e que também esta iniciativa seja validada e ressignificada em resultados práticos e concretos envolvidos nas diversas políticas públicas que tratam da matéria (a exigência de capacitação do consumidor endividado para a obtenção de algum benefício que lhe auxilie na reestruturação financeira, por exemplo), para uma maior conscientização necessária ao enfrentamento do problema social aqui apresentado.

\section{REFERÊNCIAS}

BAUERMANN, Sandra. Implantação e experiência do projeto de tratamento ao superendividamento do consumidor no Poder Judiciário do Paraná. Revista de direito do consumidor, São Paulo - Editora Revista dos Tribunais -, a. 23, vol. 95, pp. 231-251, set./out., 2014.

BRANSON, William H. Macroeconomia: teoria e política. 2.ed. Lisboa: Fundação Calouste Gulbekian, 2001.

BRASIL. Senado Federal. Projeto de lei $n^{\circ}$ 283. Altera a Lei $n^{\circ} 8.078$, de 11 de Setembro de 1990 (Código de Defesa do Consumidor), para aperfeiçoar a disciplina do crédito ao consumidor e dispor sobre a prevenção do superendividamento. Disponível em: http://www.senado.leg.br/atividade/rotinas/materia/getPDF.asp?t=112479\&tp=1. Acesso em: 08 Set. 2016.

CARVALHO, Diógenes Faria de. Consumidor endividado, vítima do sistema cultural. Revista luso-brasileira de direito do consumo, Curitiba - Editora Bonijuris, J.M. Editora -, vol. II, n. 1 - n. 5 -, pp. 55-74, jan./mar., 2012. 
CARVALHO, Fernando J. Cardim de et al. Economia monetária financeira: teoria e política. 2. ed. Rio de Janeiro: Elsevier, 2007.

CONFEDERAÇÃO NACIONAL DO COMÉRCIO. Pesquisa Nacional de Endividamento e Inadimplência do Consumidor (PEIC). Disponível em: http://www.cnc.org.br/sites/default/files/arquivos/peic_fevereiro_2016.pdf. Acesso em: 11 mar. 2016.

FACHIN, Luiz Edson. Estatuto jurídico do patrimônio mínimo. 2. ed. Rio de Janeiro: Renovar, 2006.

FARIAS, Cristiano Chaves de; ROSENVALD, Nelson. Curso de direito civil: direito das obrigações. 8. ed. v.2. Salvador: JusPODIVM, 2014.

FONSECA, João Bosco Leopoldino da. Direito econômico. Rio de Janeiro: Forense, 2010.

GAGLIANO, Pablo Stolze; PAMPLONA FILHO, Rodolfo. Novo curso de direito civil, volume 2: obrigações. 16. ed. São Paulo: Saraiva, 2015.

HERRERA, Carlos Miguel. Estado, constituição e direitos sociais. In: Revista da Faculdade de Direito da Universidade de São Paulo. São Paulo - USP, vol. 102, pp. 371-397, jan./dez., 2007.

KEYNES, John Maynard. The general theory of employment, interest and money. Cambridge: The Royal Economic Society (Maximilian), 1973.

LAPAVITSAS, Costas. El capitalismo financiarizado: Expansión y crisis. Trad.: Diego Guerrero. Madrid: Maia Ediciones, 2009.

LORENZETTI, Ricardo Luis. Comércio eletrônico. Trad. Fabiano Menke. Notas Claudia Lima Marques. São Paulo: Editora Revista dos Tribunais, 2004.

MACEDO JUNIOR, Ronaldo Porto. Contratos relacionais e defesa do consumidor. São Paulo: Editora Revista dos Tribunais, 2007.

MARQUES, Claudia Lima. Contratos no Código de Defesa do Consumidor: o novo regime das relações contratuais. 5. ed. São Paulo: Editora Revista dos Tribunais, 2005.

MORAES, Márcia Amaral Corrêa de. O impacto da mídia publicitária e relacional na formação de consumidores jovens e adultos. In: Revista luso-brasileira de direito do consumo. Curitiba - Editora Bonijuris, J.M. Editora, vol. II, n. 3 - n. 7 - pp. 95-111, jul./set., 2012.

Organisation for Economic Co-operation and Development (OECD). The financial crisis: reform and exit strategies. Disponível em: http://www.oecd.org/daf/fin/financialeducation/43091457.pdf. Acesso em: 07 set. 2016. 
SALLES, Raquel Bellini de Oliveira. O desequilíbrio da relação obrigacional e a revisão dos contratos no Código de Defesa do Consumidor: para um cotejo com o Código Civil. In: Obrigações: estudos na perspectiva civil - constitucional. Rio de Janeiro: Renovar, 2005.

SARLET, Ingo Wolfgang. A Eficácia dos direitos fundamentais. Porto Alegre: Livraria do Advogado, 2005.

SILVA, José Afonso da. Curso de direito constitucional positivo. 32. ed. São Paulo: Malheiros Editores, 2009.

SILVA, José Pereira da. Gestão e análise de risco de crédito. 6. ed. São Paulo: Atlas, 2008.

SILVA, Joseane Suzart Lopes da. Superendividamento dos consumidores brasileiros e a imprescindível aprovação do Projeto de Lei 283/2012. Revista de direito do consumidor, São Paulo - Editora Revista dos Tribunais -, a. 24, vol. 100, pp. 361-390, jul./ago., 2015.

TARTUCE, Flávio. Direito civil, v. 2: direito das obrigações e responsabilidade civil. 11. ed. Rio de Janeiro: Forense; São Paulo: MÉTODO, 2016.

TARTUCE, Flávio. Manual de direito civil: volume único. 4.ed. Rio de Janeiro: Forense / São Paulo: Método. 2014.

TORRES, Larissa Fontes de Carvalho. Responsabilidade civil das instituições financeiras: aspectos gerais e análise do projeto de lei $n^{0} 283$, que disciplina a proteção do consumidor em face do superendividamento. Reflexões críticas de Direito do Consumidor: estudos em homenagem ao professor Fernando Vasconcelos. VASCONCELOS, Fernando, et. al. (Orgs.). João Pessoa: Ideia, 2013.

PORTAL DE DEFESA DO CONSUMIDOR. Administrado por Secretaria Nacional do Consumo (SENACON). Desenvolvido em parceria entre a Secretaria Nacional do Consumo (SENACON) e a Universidade de Brasília (UnB). Apresenta ferramentas permanentes de educação, informação, orientação e capacitação na área de defesa do consumidor. Disponível em: http://www.defesadoconsumidor.gov.br/escolanacional. Acesso em 23 mar. 2017. 